\title{
Preparing for caesarean delivery from the eyes of expectant mothers and their partners: A questionnaire study
}

\section{Dear Editor,}

As the rate of caesarean delivery climbs, optimising its outcomes has become a topic of increasing relevance to clinical practice. Negative birth experiences are associated with lower quality of life and traumatic stress symptoms. ${ }^{1}$ It is therefore important to evaluate and enhance patient-centric outcomes such as overall satisfaction, in addition to clinical outcomes. A secondary study involving more than 6,000 women found that caesarean delivery itself is a significant predictor of a negative birth experience. ${ }^{1}$ Conversely, smaller primary comparative studies have reported significantly higher satisfaction and fulfilment, ${ }^{2}$ as well as lower anxiety and guilt scores ${ }^{3}$ among women who underwent planned caesarean delivery compared with women who delivered vaginally. The contrast in results is not surprising given that the experience is influenced by many factors. The findings of partners' experiences, moreover, raise concern. A systematic review of fathers' experiences found that healthcare systems tend to situate fathers in an ambivalent space, as neither patient nor visitor, diverging from their desire to be engaged and supportive in the pregnancy journey. ${ }^{4}$

Notably, there is an absence of published data on paired patients' and partners' caesarean delivery experience in our population.

To address this gap, we designed a questionnaire study among a random sample of approximately 100 couples at KK Women's and Children's Hospital, Singapore. Women and their partners above 21 years of age who had an elective caesarean delivery of a live infant and who were able to read English were invited to join the study. The primary aim was to elucidate couples' experience of preparing for delivery and to evaluate the adequacy of information provided. Secondary aims were to elucidate sources of information accessed and perceptions of their usefulness; distil valued elements in the pregnancy journey; and obtain suggestions for improvement. The questionnaire comprised separate sections for women and their partners with multiple-choice, Likert scale and open-ended questions to obtain quantitative and qualitative data. A pilot study of 20 couples was conducted to establish face validity and user friendliness of the questions.
A total of 111 couples were approached during the study period. Of this, $85(77 \%)$ responses were received. The majority $(73 / 85,86 \%)$ included responses from both women and their partners. Two-thirds of women had one or more previous caesarean sections $(54 / 85,64 \%)$, while the remaining had a primary caesarean section $(31 / 85,36 \%)$. Three-quarters of partners $(54 / 75,74 \%)$ had accompanied the woman during most or all clinic visits, antenatal classes and hospital admissions.

With regard to the preferred mode of delivery (prior to visiting the obstetrician), responses were divided between caesarean section $(24 / 85,28 \%)$, normal vaginal delivery $(30 / 85,35 \%)$ and no preference $(31 / 85,36 \%)$. The point at which the eventual decision for caesarean section was made ranged from less than 1 week $(20 / 84,24 \%)$ to more than 3 months prior to delivery $(23 / 84,27 \%)$. Among the former, the most common patient-reported indications for caesarean delivery were a combination of obstetric factors (e.g. poorly controlled maternal medical conditions, placenta previa and multiple gestations) $(5 / 20,25 \%), 1$ or more previous caesarean section(s) $(4 / 20,20 \%)$ and macrosomia $(4 / 20,20 \%)$. On the follow-up question of preparedness, a minority of women $(5 / 826 \%)$ felt they did not have enough time to think about and prepare for delivery.

As studies have demonstrated an association between unplanned caesarean delivery and a negative birth experience, ${ }^{5,6}$ the discussion on the mode of delivery should ideally be initiated early, or at least when the possibility of caesarean delivery arises, even if the final decision is made later. There may still be instances when this is not possible due to unexpected factors. Greater sensitivity, attention and support are key in these instances.

Of the plethora of information sources, doctors were the most accessed $(69 / 85,81 \%)$ and useful (26 out of 47 responses, 55\%) source of information. The latter held true among both "graduate mothers" (university/ college graduates) (12 out of 19 responses, 63\%) and "non-graduate mothers" (14 out of 28 responses, 50\%). Majority of women also reported that the information provided by healthcare professionals was adequate $(65 / 85,76 \%)$ and understood by them $(74 / 85$, 
87\%). Qualitative data revealed that women viewed information provided by doctors as reliable and they valued doctors' professional experience.

This reflects the profound degree of trust in the obstetrician-patient relationship in our population. This is similar to the findings of other studies that concluded that healthcare providers are a frequently accessed 7,8 and valued ${ }^{9}$ source of information. In fact, a survey among over 600 women who used the internet as a source for pregnancy-related information found that prior to seeking information online, almost $70 \%$ of women sought information from healthcare providers. ${ }^{10}$

In terms of discussion on the various aspects of delivery, most women could remember the risks of surgery to themselves $(67 / 85,79 \%)$ and discussion on types of anaesthesia during surgery $(56 / 85,66 \%)$, while fewer could remember being told what to expect in the post-partum unit $(25 / 85,29 \%)$ and what to expect about the recovery process $(41 / 85,48 \%)$. There was no statistical difference in overall scoring between women who underwent primary caesarean section and those who underwent repeat caesarean section $(P=0.67)$. As explaining risks has more overt medico-legal consequences if omitted, obstetricians may be focused on this aspect. Anxious mothers themselves may also be focused on obtaining and understanding information on the surgery itself as opposed to what to expect after. To address this disparity, we propose that the process of information-sharing be enriched by technology. In this study, the internet and/or social media was the second most commonly accessed (60/85, $71 \%$ ) and useful (9 out of 47 responses, 19\%) source of information. Qualitative data revealed that favourable aspects were round-the-clock accessibility, pictorial representation and reliability of hospital websites. Hence, offering patient education resources on a hospital-based website or application by leveraging audiovisual tools could complement discussions in the clinic.

Thematic analysis revealed that the best part of couples' experience was childbirth itself, and feeling supported by their partners and the healthcare team in the process (Table 1). Majority of the couples indicated "strongly agree or agree" to having the opportunity to ask questions (women: 76/85, 89\%; partners: 60/73, $82 \%$ ), feeling involved in the process of planning and preparing for delivery (women: 68/85, 80\%; partners: $59 / 73,81 \%$ ) and knowing what to expect on the day of

Table 1. Thematic analysis of women's and their partners' responses to the question on the best and worst part of their experience

Looking back, what was the best part of your experience?

\begin{tabular}{lll}
\hline & \multicolumn{1}{c}{ Patients (n=85), no. $(\mathbf{\%})$} & Partners $(\mathbf{n}=\mathbf{7 3}), \mathbf{n o .}(\mathbf{\%})$ \\
\hline Support from the healthcare team & $\begin{array}{l}37(44) \\
\text { Themes included: feeling cared for, seeing the baby } \\
\text { being taken care of, receiving prompt help, positive } \\
\text { staff attributes. }\end{array}$ & $\begin{array}{l}\text { Themes included: seeing the woman and baby being } \\
\text { taken care of, follow-up by doctors and nurses after } \\
\text { delivery, receiving prompt help, caring and friendly } \\
\text { environment. }\end{array}$ \\
$\begin{array}{ll}\text { Childbirth experience and support } \\
\text { from the partner }\end{array}$ & $\begin{array}{l}23(27) \\
\text { Themes included: seeing the baby being born safely, } \\
\text { hearing the baby cry, skin-to-skin contact with the } \\
\text { baby, having the partner present during delivery. }\end{array}$ & $\begin{array}{l}\text { Themes included: witnessing delivery of the baby, } \\
\text { knowing that the woman and baby are safe, being } \\
\text { with the woman during delivery, being a father. }\end{array}$ \\
\hline
\end{tabular}

Looking back, what was the worst part of your experience?

\begin{tabular}{|c|c|c|}
\hline & Patients $(n=85)$, no. $(\%)$ & Partners $(n=73)$, no. $(\%)$ \\
\hline Antepartum & $\begin{array}{l}13(15) \\
\text { Themes included: visiting multiple different clinics, } \\
\text { long waiting times for consultation. }\end{array}$ & $\begin{array}{l}6(8) \\
\text { Themes included: long waiting times for consultation, } \\
\text { having to leave a call-back request when calling the } \\
\text { telephone operator. }\end{array}$ \\
\hline Peripartum & $\begin{array}{l}13(15) \\
\text { Themes included: feeling nervous, partner not } \\
\text { being permitted within the operating theatre, } \\
\text { receiving the epidural and medications, } \\
\text { complications during delivery. }\end{array}$ & $\begin{array}{l}19(26) \\
\text { Themes included: waiting time between admission } \\
\text { and delivery, waiting outside the operating theatre, } \\
\text { complications during delivery. }\end{array}$ \\
\hline Postpartum & $\begin{array}{l}21(25) \\
\text { Themes included: post-procedure tiredness and pain, } \\
\text { security entry for carers and guests. }\end{array}$ & $\begin{array}{l}13(18) \\
\text { Themes included: seeing the woman in pain and tired } \\
\text { after the delivery, language barrier with staff. }\end{array}$ \\
\hline
\end{tabular}


delivery (women: 62/85, 73\%; partners: 58/73, 79\%). Most women also reported that the process of listing for caesarean delivery was smooth $(64 / 85,75 \%)$ and described staff on the day of surgery positively (79/85, 93\%), with the following descriptors most commonly used: helpful $(59 / 85,69 \%)$, patient $(23 / 85,27 \%)$, and experienced/professional (12/85, 14\%).

Almost half of women $(38 / 85,45 \%)$ and partners $(35 / 73,48 \%)$ did not report any negative experience, suggesting they had an overall positive experience. Of those who reported negative experiences, issues related to processes and logistics formed the common thread across the pregnancy journey (Table 1). This emphasises the importance of adopting systems-based style of practice. While it takes time to implement modifications to workflows or services, the healthcare team plays an integral role in pre-empting experiences or moderating patient expectations. These may be a result of obstetric factors (e.g. requiring more frequent and multidisciplinary appointments for monitoring of medical conditions in pregnancy) or system factors (e.g. postponement of elective procedures due to emergent procedures).

In conclusion, the findings of this study are a reminder for clinicians to celebrate the extraordinary experience of pregnancy and birth with each couple. We have proposed recommendations for improvement, which hopefully will keep couples at the heart of our service.

\section{Acknowledgements}

We would like to thank the postpartum ward nursing team at KK Women's and Children's Hospital for their kind assistance with recruitment.

\section{REFERENCES}

1. Smarandache A, Kim TH, Bohr Y, et al. Predictors of a negative labour and birth experience based on a national survey of Canadian women. BMC Pregnancy Childbirth 2016;16:1-9.
2. Blomquist JL, Quiroz LH, MacMillan D, et al. Mothers' satisfaction with planned vaginal and planned cesarean birth. Am J Perinatol 2011;28:383-8.

3. Wiklund I, Edman G, Larsson C, et al. First-time mothers and changes in personality in relation to mode of delivery. J Adv Nurs 2009;65:1636-44.

4. Steen M, Downe S, Bamford N, et al. Not-patient and not-visitor: a metasynthesis fathers' encounters with pregnancy, birth and maternity care. Midwifery 2012;28:422-31.

5. Rijnders $\mathrm{M}$, Baston $\mathrm{H}$, Schönbeck $\mathrm{Y}$, et al. Perinatal factors related to negative or positive recall of birth experience in women 3 years postpartum in the Netherlands. Birth 2008;35:107-16.

6. Waldenström U, Hildingsson I, Rubertsson C, et al. A negative birth experience: prevalence and risk factors in a national sample. Birth 2004;31:17-27.

7. Puia DM. The cesarean decision survey. J Perinat Educ. 2013; 22:212-25.

8. Kolip P, Büchter R. Involvement of first-time mothers with different levels of education in the decision-making for their delivery by a planned Caesarean section. Women's satisfaction with information given by gynaecologists and midwives. J Public Health 2009; 17:273-80.

9. Declercq ER, Sakala C, Corry MP, et al. Major survey findings of listening to Mothers SM III: New mothers speak out: Report of National Surveys of Women's Childbearing Experiences Conducted October-December 2012 and January-April 2013. J Perinat Educ 2014;23:17-24.

10. Lagan BM, Sinclair M, George Kernohan W. Internet use in pregnancy informs women's decision making: a web-based survey. Birth 2010;37:106-15.

Lavisha S Punjabi ${ }^{1}{ }_{M B B S}$, Lional Karunamary ${ }^{2}{ }_{M R C O G \text {, }}$ Shephali Tagore ${ }^{2}{ }_{F R C O G}$, Manisha Mathur ${ }^{1}{ }^{\text {FRCOG }}$

\author{
${ }^{1}$ Department of Obstetrics and Gynaecology, KK Women's and \\ Children's Hospital, Singapore \\ ${ }^{2}$ Department of Maternal and Fetal Medicine, KK Women's and \\ Children's Hospital, Singapore
}

Correspondence: Dr Manisha Mathur, Department of Obstetrics and Gynaecology, KK Women's and Children's Hospital, 100 Bukit Timah Rd, Singapore 229899.

Email: manisha.mathur@singhealth.com.sg 